\title{
Comparison of the trend moment and double moving average methods for forecasting the number of dengue hemorrhagic fever patients
}

\author{
Dyna Marisa Khairina ${ }^{1}$, Rizka Khairunnisa ${ }^{2}$, Heliza Rahmania Hatta ${ }^{3}$, Septya Maharani ${ }^{4}$ \\ ${ }^{1,4}$ Department of Information System, Mulawarman University, Indonesia \\ ${ }^{2,3}$ Department of Informatics, Mulawarman University, Indonesia
}

\begin{tabular}{l}
\hline \hline Article Info \\
\hline Article history: \\
Received Sep 20, 2020 \\
Revised Nov 16, 2020 \\
Accepted Dec 11, 2020 \\
\hline
\end{tabular}

\section{Keywords:}

Dengue hemorrhagic fever

Double moving average

Forecasting

Trend moment

\begin{abstract}
Spread of dengue hemorrhagic fever (DHF) is influenced by an increase in air temperature due to changes in weather and population density so that there is a lot of exchange of dengue virus through the bite of the Aedes aegypti mosquito. Forecasting models are needed to predict the number of DHF patients in the future so that monitoring of the number of DHF patients can be carried out as anticipation and consideration of decision making. Forecasting the number of patients is based on actual data within 2 (two) previous years by comparing the two methods, namely trend moment and double moving average. To measure the accuracy of the forecasting results from the two forecasting methods, tracking signal and moving range are used. based on the test results, it shows that the forecasting results are said to be good because no one has passed the upper control limit and lower control limit values so that the difference between the actual data and the forecasting results is not too significant and the trend moment more recommended because the difference in actual data and forecasting results are approached and shown in the pattern graph by looking at the data difference in each period.
\end{abstract}

This is an open access article under the CC BY-SA license.

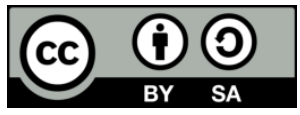

\section{Corresponding Author:}

Dyna Marisa Khairina

Department of Information System

Mulawarman University

Sambaliung Road, Gunung Kelua Campus, Samarinda Country, East-Kalimantan, Indonesia

Email: dyna.ilkom@gmail.com

\section{INTRODUCTION}

Predictions of future events are rarely made with certainty and can, at best, be described in probabilistic terms [1]. Forecasting is important and applicable to business and industry, government, economics, medicine, social, politics, environment, accounting, and others [2]. Forecasting can also be applied to predict the health sector or in this case predict the number of dengue fever patients by looking at data and information in the past. From that definition, forecasting has a procedure, namely [2, 3]: (i) Problem analyze; (ii) Collecting data; (iii) Analyze the data collected; (iv) Selecting the appropriate method; (v) Testing of selected methods; (vi) Using the method; (vii) Monitor performance of forecasting methods. From the forecasting procedure that has been described then in this study conducted a comparison test method and forecasting method performance by measuring the accuracy and accuracy of forecasting results.

Forecasting is the knowledge and art to predict what will be happened in the future at the present time. In doing the forecasting, it must contain data and information of the past. Past data and information are behavior that occurs along with various conditions at that time [4]. There are prediction methods that are qualitative and quantitative. Qualitative forecasting is based on the assumption of management, market research, structured group and historical analogies. In most cases quantitative forecasting method such as 
statistics method has successfully applied to forecast continuous data such as in stock market, price forecasting, inventory system, global horizontal irradiance, supply and demand system [5-9]. A short-term forecast can evaluate the possible epidemic trend in the future in a timely and effective manner, and improve current preventive measures [10]. Time series analysis is a scientific quantitative forecast method that has been widely used in many fields, such as in forecasting the number of new inpatient admissions [11], medical costs [12], the price of gold, and water consumption expenditure [13]. A time series is said to have a complex seasonal pattern when it has trend and multiple seasonal patterns, perhaps with non-integer period. Recently, this kind of series has been intriguing researchers to study and develop method to improve the forecast accuracy [14]. There is a unifying theory or the so-called golden rule of forecasting. The Golden Rule of Forecasting is to be conservative. A conservative forecast is consistent with cumulative knowledge about the present and the past. To be conservative, forecasters must seek out and use all knowledge relevant to the problem, including knowledge of methods validated for the situation [15].

Dengue fever according to data compiled by the Ministry of Health of the Republic of Indonesia has become an endemic disease in Indonesia. This disease is one of the main problems in Indonesia, with the spread and number of sufferers tending to increase every year. Throughout 2017, there were around 59,000 cases of dengue fever throughout Indonesia, with more than 400 of them ending in death. Because of its large population, Central Java and East Java Provinces accounted for the largest number of dengue hemorrhagic fever (DHF) cases for 2017, which was more than 7000 cases in each province. Dengue fever is often found especially in the tropics and often causes extraordinary events. Some factors that influence the emergence of DHF include low immune status of community groups and population densities of infectious mosquitoes due to the many mosquito breeding sites that usually occur in the rainy season. In recent years, cases of DHF often appear in the transition season. In 2014, there were 71,668 sufferers of DHF in 34 provinces in Indonesia, and 641 of them died. This number is lower than the previous year, namely in 2013 with a total of 112,511 people and a total of 871 patients died [16].

Dengue is one of the most common tropical diseases affecting humans. Dengue has become a major interna-tional problem in public health in recent decades. The world health organization (WHO) estimates that around $2.5 \mathrm{e} 3$ billion people are presently living in dengue trans-mitted zones [17]. DHF is a vector borne disease that is transmitted through the bite of Aedes sp. mosquitoes infected with Dengue virus. Due to its contribution to the disease burden, high mortality rates, poverty, and social burden in the world, especially intropical and subtropical regions, DHF is still a major global problem [18]. The research objective is to identify and predict the number of DHF patients in the future and analyze the results of forecasting the number of DHF patients based on the calculation of the number of patients each month for the previous 2 years by comparing the use of the trend moment and double moving average methods to be used in making decisions and know the advantages of the best method in predictions or forecasting then measure the accuracy of the forecast results. The results of forecasting are used in decision making both for planning the supply of equipment and adequate drug supplies for patients.

Several studies related to forecasting using the trend moment and moving range method include forecasting the application of the trend moment method for stock prediction as production support by analyzing sales trends is then combined with the season index method. Testing using the mean absolute percentage error (MAPE) method shows the trend moment produces an error value of $10.60 \%$, while the combination of the trend moment method with the season index results in an error of $7.83 \%$, so it is concluded that the effect of the season index can reduce forecasting errors a value of $2.77 \%$ [19]. Trend moment for predicting the rental of multimedia equipment using data 2 years earlier and resulting in an error rate of $21 \%$ [20]. Data mining analysis for forecasting the total delivery of goods using data from the last 5 periods and producing accuracy using MAPE as a testing method with a yield of 34\% [21] and researching forecasting to predict rice prices using the autoregressive integrated moving average with exogeneous (ARIMAX) model and the vector autoregressive (VAR) model involving several variables, including consumer rice price, production, dry milled rice, harvested area and rice prices in Thailand. The results of the study show that the ARIMAX model can predict the consumer price of rice with a MAPE of $0.15 \%$ and this is $15.27 \%$ better than the VAR model [22]. The study also made a model comparison method for forecast rice production in Indonesia using exponential smoothing and neural networks and then evaluated the error using MAPE and mean square error (MSE) which resulted in MAPE and MSE values that were lower by $6.7 \%$ and $1.5 \%$ compared to using statistical methods [23]. Research by comparing double moving average and double exponential smoothing method in number forecasting foreign tourists who come to North Sumatra using 108 data from January 2010 to December 2018 which shows the results on DMA have the smallest MAPE value, namely $14.12 \%$ while the DES Brown method with and DES Holt produced MAPE values respectively $12.71 \%$ and $12.21 \%$ [24]. 


\section{RESEARCH METHOD}

\subsection{Trend moment}

Trend moment method includes forecasting method which in its technique uses statistical calculations and certain mathematical calculations aims to determine the straightline function instead of the dashed line formed by the company's historical data. In this moment trend method, there is a combination of statistical analysis in the form of trend analysis and moment method [25]. The used trend equation is shown in (1):

$$
\mathrm{Y}=\mathrm{a}+\mathrm{bX}
$$

where $\mathrm{Y}$ is the value of the trend (forecasting); $\mathrm{a}$ as a constant number; $\mathrm{b}$ as a slope or trend line inclination coefficient; and $\mathrm{X}$ shows the time index $(\mathrm{X}=0,1,2,3, \ldots, \mathrm{n})$. With the mathematical method, the values a and $\mathrm{b}$ of the above linear trend equations are determined by using the following normal equations shown in (2) and (3):

$$
\begin{aligned}
& \mathrm{b}=\frac{\mathrm{n}(\Sigma \mathrm{XY})-(\Sigma \mathrm{X})(\Sigma \mathrm{Y})}{\mathrm{n}\left(\Sigma X^{2}\right)-(\Sigma \mathrm{X})^{2}} \\
& \mathrm{a}=\frac{\Sigma \mathrm{Y}-\mathrm{b}(\Sigma \mathrm{X})}{\mathrm{n}}
\end{aligned}
$$

where $\Sigma Y$ is the cumulative number of data on the number of DHF patients; $\Sigma \mathrm{X}$ is the sum of time periods; and $\Sigma X Y$ is the number of data the number of patients multiplied by time period. The $n$ indicates the number of data on the number of patients.

Forecast values that have been obtained from forecasting results with the trend moment method will be corrected for seasonal influences using the season index. The use of trend moment method can still be improved the results of forecasting using season index factors. Season index is a periodic series that has regular movements and almost happens at certain times, considered to have seasonal movement. Ordinary movements are influenced by certain variables that have a seasonal relationship due to natural conditions as well as factors of human activity [19]. Ordinary movements are influenced by certain variables that have a seasonal relationship due to natural conditions as well as factors of human activity. The following seasonal index formula that can be used is shown in (4):

$$
\text { Season Index }=\frac{\text { Average demand for a particular month }}{\text { Average monthly demand }}
$$

To get the final forecast results after being influenced by the season index the equation is calculated in (5).

$$
\mathrm{Y}^{*}=\text { Season Index } . \mathrm{Y}
$$

where $\mathrm{Y}^{*}$ shows the forecast results using the trend moment method which is influenced by the season index and $\mathrm{Y}$ shows the forecast results using the trend moment.

\subsection{Double moving average}

The moving average model uses a number of new actual request data to generate forecast values for future requests. The moving average method will be effectively applied if market demand for products is assumed to be stable over time. To get forecast results in the coming period, historical data is needed for a certain period. For example with the 3 month moving average method, the 4th month forecast can only be calculated after the 3rd month ends, and so on [26].

The double moving average method was found to overcome the shortcomings that exist in the simple average and single moving average methods. If the simple average and single moving average methods cannot cope if a trend occurs, then the double moving average method can handle them better. The basis of the double moving average method is to calculate the second moving average. The formula used for the single moving average and double moving average methods is as (6):

$$
\begin{aligned}
& S^{\prime}{ }_{t}=\frac{X t+x t-1+\cdots X(t+1)-n}{n} \\
& S^{\prime \prime}{ }_{t=} \frac{S^{\prime} t+S^{\prime} t-1+\cdots S^{\prime}(t+1)-n}{n} \\
& \mathrm{a}_{t=} 2 S^{\prime}{ }_{t}-S^{\prime}{ }_{t}
\end{aligned}
$$




$$
\begin{aligned}
& \mathrm{b}_{t}=\frac{2}{n-1}\left(S_{t}^{\prime}-S_{t}{ }^{\prime}\right) \\
& F_{t+m=} \mathrm{a}_{t}+\mathrm{b}_{t} \mathrm{~m}
\end{aligned}
$$

where $\mathrm{X}_{t}$ shows the data in period $\mathrm{t}, \mathrm{n}$ as an order, $\mathrm{S}_{t}{ }_{t}$ is the first average value of period $\mathrm{t}$ and $\mathrm{S}^{\prime}{ }_{t}$ is the second average value of period $\mathrm{t}$. The $\mathrm{a}_{t}$ indicates interception in the period $\mathrm{t}, \mathrm{b}_{t}$ shows the trend value of the period $\mathrm{t}$ and $\mathrm{F}_{t+m}$ is a forecast in the period $t+m$.

\subsection{Tracking signal}

Tracking signal is a measure of how well a forecast estimates the actual values of a forecast updated every week, month or quarter, so that new demand data is compared against forecast values. The tracking signal is calculated as the running sum of the forecast errors (RSFE) divided by the mean absolute deviation (MAD) [27].

$$
\text { Tracking Signal }=\frac{R S F E}{M A D}
$$

The RSFE value is the cumulative amount of the difference between the actual data and the forecast results for each period while MAD is the ratio between the absolute cumulative error with each period. A positive tracking signal indicates that the actual value is greater than the forecast value while a negative tracking signal indicates the actual value is smaller than the forecast value. A tracking signal is called good if it has a low RSFE, and has as many positive errors or is balanced by negative errors, so that the center of the tracking signal is close to zero. If the tracking signal has been calculated, then the control signal tracking map can be built as is the case with the control maps in controlling statistical processes, which have the upper control limit (UCL) and the lower control limit (LCL). It is recommended by production planning and inventory control (PPIC) experts, Plossl and Wight, that use a maximum tracking signal value \pm 4 , as the control limits for tracking signals [28]. Thus, if the tracking signal is outside the control limits, forecasting models need to be reviewed, because forecasting accuracy cannot be accepted. And if the tracking signal is within the control limits, the calculation can be continued [27].

\subsection{Moving range}

Moving range is made to compare observational values or actual data with forecast values of the same needs. It can be said that moving range is a statistical control map used in quality control. Moving range maps have limits consisting of the UCL and the LCL. If there is a point or data that is outside this limit then there is some data that must be removed or look for other forecasting methods. Moving range is used to find out the direction of movement. Moving range calculation uses the formula:

$$
\text { Moving Range }(\mathrm{MR})=|(F t-1-A t-1)-(F t-A t)|
$$

UCL and LCL values for moving range are different from UCL and LCL for other methods. The moving range method has its own formula for determining UCL and LCL, i.e.:

$$
\begin{aligned}
& \mathrm{UCL}=+2.66 * \mathrm{MR} \\
& \mathrm{LCL}=-2.66 * \mathrm{MR}
\end{aligned}
$$

with

$$
M R=\sum \frac{M R}{n-1}
$$

\section{RESULTS AND DISCUSSION}

\subsection{Data collection}

Model of forecasting the number of DHF patients is designed to identify and predict the number of DHF patients in the future and analyze the results of forecasting the number of DHF patients by comparing the use of two methods, namely the trend moment method and the double moving average method. After the results of forecasting the number of patients for 2018 using these two methods, then the comparison of forecast data for the 2018 patients is compared with the actual data of the number of patients with DHF in 2018 by calculating the accuracy value using the tracking signal and moving range method.

The data used are data on the number of DHF patients at the Muara Badak Health Center for the previous 2 years, from January 2016 to December 2017. Data on the number of DHF patients within the 2 
years period came from surveillance officers at the Muara Badak Health Center [29]. This data then becomes the basis for forecasting the following year. Table 1 presents the data that will be used in forecasting namely the number of patients from January to December for the last 2 years from January 2016 to December 2016 to January 2017 to December 2017.

Table 1. Data on the number of DHF patients [29]

\begin{tabular}{cccc}
\hline \multirow{2}{*}{ Month } & \multicolumn{3}{c}{ Year } \\
\cline { 2 - 4 } & 2016 & 2017 & 2018 \\
\hline January & 3 & 2 & 0 \\
February & 2 & 6 & 7 \\
March & 1 & 3 & 1 \\
April & 4 & 8 & 7 \\
May & 6 & 1 & 4 \\
June & 1 & 4 & 3 \\
July & 7 & 3 & 5 \\
August & 2 & 7 & 1 \\
September & 5 & 2 & 7 \\
October & 1 & 4 & 4 \\
November & 7 & 1 & 1 \\
December & 4 & 3 & 6 \\
Amount & $\mathbf{4 3}$ & $\mathbf{4 4}$ & $\mathbf{4 6}$ \\
\hline
\end{tabular}

\subsection{Forecasting using the trend moment method}

As a first step, forecasting tests are carried out using the trend moment method to find out the comparison between forecast results and actual data for the number of patients in 2018 using data on the number of patients in 2016 to 2017. The forecasting data is conducted using data on the number of patients in 2016 until 2017 to predict the number of patients in 2018 can be seen in Table 2. The results of forecasting trials using the Trend Moment method for the number of patients in 2018 can be seen in Table 3 .

Table 2. Data on the number of DHF patients for 2018 forecasting using the trend moment method

\begin{tabular}{|c|c|c|c|c|c|}
\hline Month & Year & $\mathrm{X}$ (time index) & Y (number of patients) & $\mathrm{XY}$ & $\mathrm{X}^{2}$ \\
\hline January & & 0 & 3 & 0 & 0 \\
\hline February & & 1 & 2 & 2 & 1 \\
\hline March & & 2 & 1 & 2 & 4 \\
\hline April & & 3 & 4 & 12 & 9 \\
\hline May & & 4 & 6 & 24 & 16 \\
\hline June & 2016 & 5 & 1 & 5 & 25 \\
\hline July & 2016 & 6 & 7 & 42 & 36 \\
\hline August & & 7 & 2 & 14 & 49 \\
\hline September & & 8 & 5 & 40 & 64 \\
\hline October & & 9 & 1 & 9 & 81 \\
\hline November & & 10 & 7 & 70 & 100 \\
\hline December & & 11 & 4 & 44 & 121 \\
\hline January & & 12 & 2 & 24 & 144 \\
\hline February & & 13 & 6 & 78 & 169 \\
\hline March & & 14 & 3 & 42 & 196 \\
\hline April & & 15 & 8 & 120 & 225 \\
\hline May & & 16 & 1 & 16 & 256 \\
\hline June & 2017 & 17 & 4 & 68 & 289 \\
\hline July & 2017 & 18 & 3 & 54 & 324 \\
\hline August & & 19 & 7 & 133 & 361 \\
\hline September & & 20 & 2 & 40 & 400 \\
\hline October & & 21 & 4 & 84 & 441 \\
\hline November & & 22 & 1 & 22 & 484 \\
\hline December & & 23 & 3 & 69 & 529 \\
\hline Amount & & 276 & 87 & 1014 & 4324 \\
\hline Average & & 11.50 & 3.63 & & \\
\hline
\end{tabular}

Steps of the calculation process using the trend moment method for data on the number of dengue fever patients:

a. Calculation to find the values of $b$ and a using (2) and (3)

b. Calculations to find the value of Trend (Y) in 2018 using (1)

c. Calculation of Season Index using (4) 
d. Final calculation of forecasting results using (5)

From the forecasting results in Table 3 then a comparison of actual data and forecasting data for the number of DHF patients in 2018 can be seen in Table 4.

Table 3. Results of forecasting the number of DHF patients using the trend moment method for 2018

\begin{tabular}{cc}
\hline Month & 2018 \\
\hline January & 3 \\
February & 4 \\
March & 2 \\
April & 6 \\
May & 4 \\
June & 3 \\
July & 5 \\
August & 5 \\
September & 4 \\
October & 3 \\
November & 4 \\
December & 4 \\
Amount & $\mathbf{4 7}$ \\
\hline
\end{tabular}

Table 4. Comparison of actual data and forecasting data on number of DHF patients using the trend moment method for 2018

\begin{tabular}{ccc}
\hline \multirow{2}{*}{ Month } & \multicolumn{2}{c}{2018} \\
\cline { 2 - 3 } & Actual data & Forecasting data \\
\hline January & 0 & 3 \\
February & 7 & 4 \\
March & 1 & 2 \\
April & 7 & 6 \\
May & 4 & 4 \\
June & 3 & 3 \\
July & 5 & 5 \\
August & 1 & 5 \\
September & 7 & 4 \\
October & 4 & 3 \\
November & 1 & 4 \\
December & 6 & 4 \\
Amount & $\mathbf{4 6}$ & $\mathbf{4 7}$ \\
\hline
\end{tabular}

\subsection{Forecasting using the double moving average method}

Forecasting using the double moving average method also compares the forecasting data with actual data for the number of patients in 2018. Forecasting data using the double moving average method is performed using data on the number of patients in 2016 through 2017 to predict the number of patients in 2018, as in Table 1. The results of forecasting can be seen in Table 5 and comparison of actual data and forecasting data using the double moving average method for the number of patients in 2018 can be seen in Table 6. The step of the calculation process uses the double moving average method for data on the number of dengue hemorrhagic fever patients:

a. Calculation to determine the number of periods or months $(m)$

b. Calculation to find the value of single moving average $\left(S^{\prime} t\right)$ using (6)

c. Calculation to find the value of double moving average $\left(S^{\prime \prime} t\right)$ using (7)

d. Calculations look for constant values for m periods (months ahead) using (8)

e. Calculations look for the value of the trend coefficient (the slope coefficient of the trend equation) using (9)

f. Final calculation of forecasting results using (10)

From the forecasting results in Table 5 then a comparison of actual data and forecasting data for the number of DHF patients in 2018 can be seen in Table 6.

Table 5. Results of forecasting the number of DHF patients using the double moving average method for 2018

\begin{tabular}{cc}
\hline Month & 2018 \\
\hline January & 2 \\
February & 0 \\
March & 4 \\
April & 4 \\
May & 6 \\
June & 1 \\
July & 4 \\
August & 3 \\
September & 8 \\
October & 3 \\
November & 4 \\
December & 5 \\
Amount & $\mathbf{4 4}$ \\
\hline
\end{tabular}

Table 6. Comparison of actual data and forecasting data on number of DHF patients using the double moving average method for 2018

\begin{tabular}{ccc}
\hline \multirow{2}{*}{ Month } & \multicolumn{2}{c}{2018} \\
\cline { 2 - 3 } & Actual data & Forecasting data \\
\hline January & 0 & 2 \\
February & 7 & 0 \\
March & 1 & 4 \\
April & 7 & 4 \\
May & 4 & 6 \\
June & 3 & 1 \\
July & 5 & 4 \\
August & 1 & 3 \\
September & 7 & 8 \\
October & 4 & 3 \\
November & 1 & 4 \\
December & 6 & 5 \\
Amount & $\mathbf{4 6}$ & $\mathbf{4 4}$ \\
\hline
\end{tabular}

\subsection{Comparison of forecasting results of the trend moment method and the double moving average} method

Comparison of forecasting results of the two methods is done by calculating the accuracy of forecasting results as a step to see the errors made in forecasting. Obtaining an accuracy value is used the 
tracking signal and moving range methods to measure the accuracy of forecasting results generated from the two forecasting methods used as consideration in making decisions. Table 7 shows the forecasting results of the two methods along with the actual data. From Table 7 it can be calculated tracking signal and moving range to get the accuracy value of the forecasting accuracy using (11) and (12). The accuracy results are presented in Table 8 for the trend moment method and Table 9 for the double moving average method.

Table 7. Comparison of actual data and forecasting data on number of DHF patients using the trend moment and double moving average methods for 2018

\begin{tabular}{cccc}
\hline Month & $\begin{array}{c}\text { Actual } \\
\text { data }\end{array}$ & $\begin{array}{c}\text { Trend moment } \\
\text { forecasting }\end{array}$ & $\begin{array}{c}\text { Double moving average } \\
\text { forecasting }\end{array}$ \\
\hline January & 0 & 3 & 2 \\
February & 7 & 4 & 0 \\
March & 1 & 2 & 4 \\
April & 7 & 6 & 4 \\
May & 4 & 4 & 6 \\
June & 3 & 3 & 1 \\
July & 5 & 5 & 4 \\
August & 1 & 5 & 3 \\
September & 7 & 4 & 8 \\
October & 4 & 3 & 3 \\
November & 1 & 4 & 4 \\
December & 6 & 4 & 5 \\
Amount & 46 & 47 & 44 \\
\hline
\end{tabular}

Table 8. Accuracy value of tracking signal and moving range results of forecasting the number of DHF patients using the trend moment method for 2018

\begin{tabular}{ccccc}
\hline Month period & Actual data & $\begin{array}{c}\text { Trend moment } \\
\text { forecasting }\end{array}$ & $\begin{array}{c}\text { Tracking } \\
\text { signal }\end{array}$ & Moving range \\
\hline January & 0 & 3 & -1 & - \\
February & 7 & 4 & 0 & 6 \\
March & 1 & 2 & -0.43 & 4 \\
April & 7 & 6 & 0 & 2 \\
May & 4 & 4 & 0 & 1 \\
June & 3 & 3 & 0 & 0 \\
July & 5 & 5 & 0 & 0 \\
August & 1 & 5 & -2.67 & 4 \\
September & 7 & 4 & -0.6 & 7 \\
October & 4 & 3 & 0 & 2 \\
November & 1 & 4 & -1.74 & 4 \\
December & 6 & 4 & -0.57 & 5 \\
\hline
\end{tabular}

Table 9. Accuracy value of the tracking signal and moving range results forecasting the number of DHF patients using the double moving average method for 2018

\begin{tabular}{ccccc}
\hline Month period & Actual data & $\begin{array}{c}\text { Double moving average } \\
\text { forecasting }\end{array}$ & $\begin{array}{c}\text { Tracking } \\
\text { signal }\end{array}$ & Moving range \\
\hline January & 0 & 2 & -1 & - \\
February & 7 & 0 & 1.11 & 9 \\
March & 1 & 4 & 0.5 & 10 \\
April & 7 & 4 & 1.33 & 6 \\
May & 4 & 6 & 0.88 & 5 \\
June & 3 & 1 & 1.58 & 4 \\
July & 5 & 4 & 2.1 & 1 \\
August & 1 & 3 & 1.45 & 3 \\
September & 7 & 8 & 1.17 & 1 \\
October & 4 & 3 & 1.67 & 2 \\
November & 1 & 4 & 0.41 & 4 \\
December & 6 & 5 & 0.86 & 4 \\
\hline
\end{tabular}

\subsection{Chart analysis of tracking signal patterns and moving range}

As has been presented in Tables 8 and 9, the results of the forecasting are then presented in a graphic pattern that shows the accuracy of the results of forecasting the number of DHF patients that have been done. The chart of the tracking signal pattern using the trend moment method is presented in Figure 1 
and the chart of the tracking signal pattern using the double moving average method is presented in Figure 2, both graphs produce information about the presence or absence of a value out of the UCL of 4 and the limit LCL of -4 .

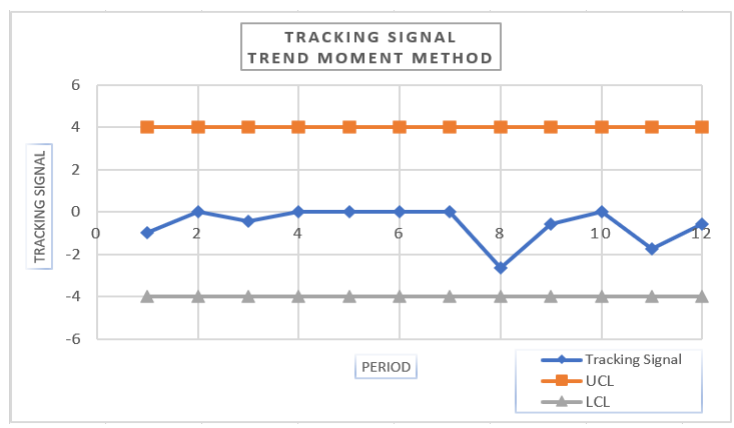

Figure 1. Tracking signal pattern chart for trend moment method

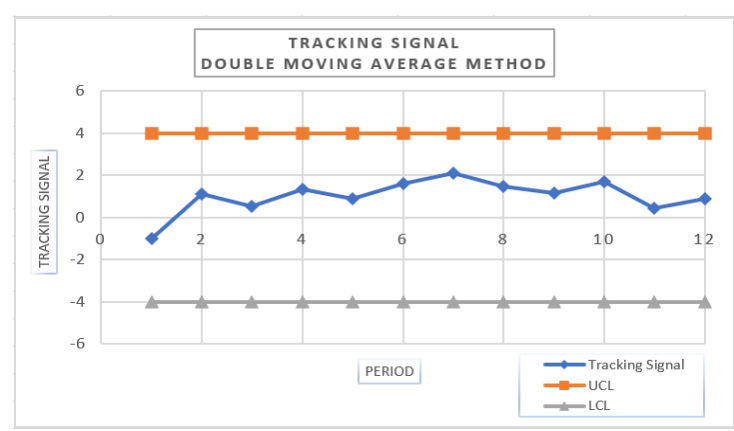

Figure 2. Tracking signal pattern chart for the double moving average method

From the chart of the tracking signal pattern using the trend moment and double moving average methods in Figures 1 and 2 show that the forecasting data can be said to be good because no one has crossed the UCL and LCL values, which are 4 and -4 . Furthermore, the moving range accuracy value from the results of forecasting the number of DHF patients from Tables 8 and 9 is also presented in the form of a graphic pattern that shows the accuracy of a forecast number of DHF patients. The moving range pattern chart using the trend moment method is presented in Figure 3 and the moving range pattern chart using the double moving average method is presented in Figure 4 which is shown by the magnitude of A-f which shows the difference between the actual data and the results of forecasting.

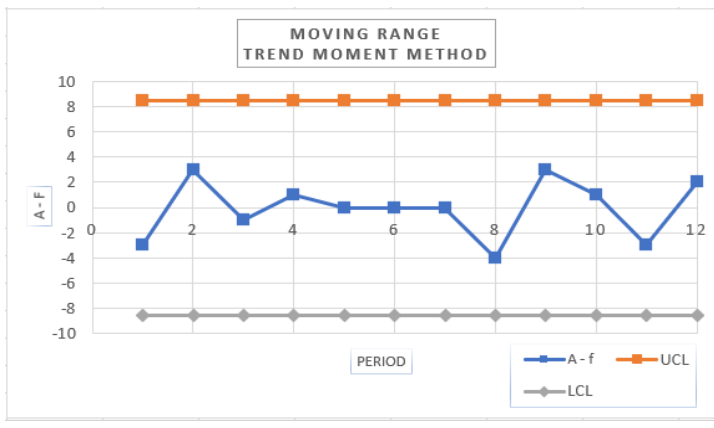

Figure 3. Moving range pattern chart for the trend moment method

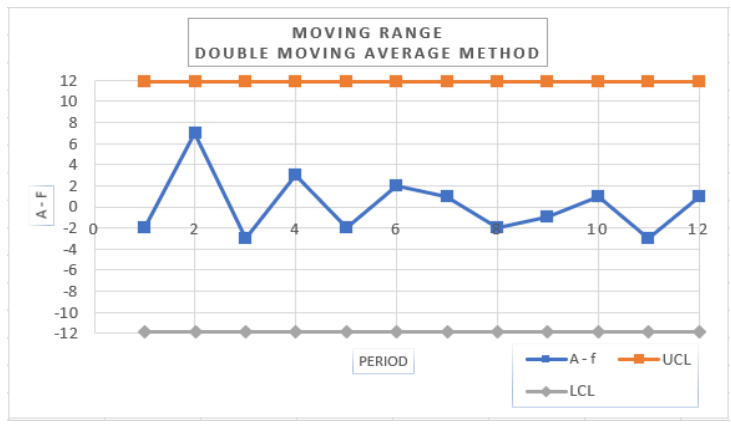

Figure 4. Moving range pattern chart for the double moving average method

From the moving range pattern chart using the trend moment and double moving average methods in Figures 3 and 4 show that none of the forecasting data came out or passed through the UCL and LCL. The UCL and LCL values in the moving range are obtained by using (13) and (14) so that based on the moving range pattern graph in Figures 3 and 4 between the actual data and forecasting results there is no significant difference.

\section{CONCLUSION}

Forecasting results using the trend moment and double moving average methods are presented in the form of chart patterns to measure the accuracy of forecasting results using tracking signal and moving range which shows that forecasting results are said to be good because no one has passed the upper limit of the UCL and LCL so that the difference between the actual data and forecasting results is not too significant. As for the two trend moment and double moving average methods, it can be concluded that the trend moment method has more advantages than the double moving average method because the difference in actual data and forecasting results are close to and also shown in the pattern chart by looking at the difference in data in 
each period. Based on this, it is recommended to use the trend moment method as an approach to predict the number of DHF patients in the following years in anticipation of uncertainty in the number of DHF patients as a follow-up plan for decision makers in making policies to anticipate the increasing number of DHF patients from year to year.

\section{REFERENCES}

[1] S. M. Hohle and K. H. Teigen, "Forecasting forecast: The trend effect," Judgment and Decision Making, vol. 10, no. 5, pp. 416-428, 2015.

[2] D. C. Montgomery, C. L. Jennings, and M. Kulahci, "Introduction to time series analysis and forecasting," Canada: John Wiley and Sons, Inc, pp. 1-671, 2015.

[3] A. C. Vallet, J. D. Bermúdez, and E. Vercher, "Forecasting correlated time series with exponential smoothing models," International Journal of Forecasting, vol. 27 no. 2, pp. 252-265, 2011

[4] D. M. Khairina, A. Muaddam, S. Maharani, and H. Rahmania, "Forecasting of groundwater tax revenue using single exponential smoothing method," The 4th Internasional Conference on Energi, Environment, Epidemiology and Information System (ICENIS), Semarang-Indonesia, vol. 125, pp. 1-5, 2019.

[5] E. L. de Faria, M. P. Albuquerque, J. L. Gonzalez, J. T. P. Cavalcante, and M. P. Albuquerque, "Predicting the Brazilian stock market through neural networks and adaptive exponential smoothing methods," Expert System with Applications, vol. 36, no. 10, pp. 12506-12509, Dec. 2009.

[6] L. Wu, S. Liu, and Y. Yang, "Grey double exponential smoothing model and its application on pig price forecasting in China," Applied Soft Computing, vol. 39, pp. 117-123, 2016.

[7] G. Sbrana and A. Silvestrini, "Random switching exponential smoothing and inventory forecasting," International Journal Production Economics Elsevier, vol. 156, pp. 283-294, 2014.

[8] D. Yang, V. Sharma, Z. Ye, L. I. Lim, L. Zhao, and A. W. Aryaputera, "Forecasting of global horizontal irradiance by exponential smoothing, using decompositions," Energy, vol. 81, no. 1, pp. 111-119, 2015.

[9] F. Poloni and G. Sbrana, "A note on forecasting demand using the multivariate exponential smoothing framework," International Journal of Production Economics, vol. 162, pp. 143-150, 2015.

[10] P. Guan, W. Wu, and D. Huang, "Trends of reported human brucellosis cases in main-land China from 2007 to 2017: An exponential smoothing time series analysis," Environ. Health Preventive Med., vol. 23, no. 1, pp. 1-7, 2018.

[11] L. Zhou, P. Zhao, D. Wu, C. Cheng, and H. Huang, "Time series model for forecasting the number of new admission inpatients," BMC Med. Inf. Decis. Making, vol. 18, no. 1, pp. 1-11, 2018.

[12] S. Wang, M. Petzold, J. Cao, Y. Zhang, and W. Wang, "Direct medical costs of hospitalization for cardiovascular diseases in shanghai, China," Medicine, vol. 94, no. 20, pp. 1-8, 2015.

[13] S. N. A. M. Razali, M. S. Rusiman, N. I. Zanawi, and N. Arbin, "Forecasting of water consumption expenditure using holt-winter's and ARIMA," Journal of Physics: Conference Series, vol. 995, no. 1, p. 012041, 2018.

[14] W. Sulandari, S. Subanar, S. Suhartono, H. Utami, M. H. Lee, and P. C. Rodrigues, "SSA-based hybrid forecasting models and applications," Bulletin of Electrical Engineering and Informatics, vol. 9, no. 5, pp. 2178-2188, 2020.

[15] J. S. Armstrong, K. C. Green, and A. Graefe, "Golden rule of forecasting: Be conservative," Journal of Business Research, Elsevier, vol. 68, no. 8, pp. 1717-1731, 2015.

[16] W. Anggraeni, I. P. A. A. Pramana, F. Samopa, E. Riksakomara, R. P. Wibowo, L. Condro T. and Pujiadi "Forecasting the number of dengue fever cases in Malang regency Indonesia using fuzzy inference system models," Journal of Theoretical and Applied Information Technology, vol. 95, no. 1, pp. 1-8, 2016.

[17] W. H. Wang, A. N. Urbina, M. R. Chang, W. Assavalapsakul, P. L. Lu, Y. H. Chen, and S. F. Wang, "Dengue hemorrhagic fever-A systemic literature review of current perspectives on pathogenesis, prevention and control," Journal of Microbiology, Immunology and Infection, Science Direct, vol. 53, no. 6, pp. 963-978, 2020.

[18] W. Wanti, R. Yudhastuti, H. B. Notobroto, S. Subekti, O. Sila, R. H. Kristina, and F. Dwirahmadi, "Dengue hemorrhagic fever and house conditions in kupang city, East Nusa Tenggara province," Kesmas: National Public Health Journal, vol. 13, no. 4, pp. 176-181, 2019.

[19] B. P Candra, and H. A. Fatta, "Implementation of trend moment method for stock prediction as supporting production," IOP Science Journal of Phsysics: Conference Series, vol. 1140, no. 1, pp. 1-8, 2018.

[20] A. A. F. D. Izz, M. Sholihin, and M. Masruroh,"Trend moment method for predicting multimedia equipment rental needs," Scientific Journal on Information and Communication Technology, vol. 5, no. 1, pp. 20-24, 2020.

[21] M. A. Maricar, P. Widiadnyana, and I. Wijaya, "Analysis of data mining for forecasting total goods delivery with moving average method," International Journal of Engineering and Emerging Technology, vol. 2, no. 1, pp. 7-10, 2017.

[22] W. Anggraeni, K. B. Andri, and F. Mahananto, "The performance of ARIMAX model and vector autoregressive (VAR) model in forecasting strategic commodity price in Indonesia," Procedia Computer Science, Elsevier, vol. 124, pp. 189-196, 2017.

[23] G. Airlangga, A. Rachmat, and D. Lapihu, "Comparison of exponential smoothing and neural network method to forecast rice production in Indonesia," TELKOMNIKA Telecommunication Computing Electronics and Control, vol. 17, no. 3, pp. 1367-1375, 2019.

[24] D. Febrian, S. I. Al Idrus, D. A. J. Nainggolan, “The comparison of double moving average and double exponential smoothing methods in forecasting the number of foreign tourists coming to North Sumatera," IOP Science Journal of Phsysics: Conference Series, vol. 1462, pp. 1-10, 2020. 
[25] J. Schachter and P. Mancarella, "A short-term load forecasting model for demand response applications," 11th International Conference on the European Energy Market (EEM14), IEEE, Krakow, pp. 1-5, 2014.

[26] R. Nau, "Forecasting with moving averages," Fuqua School of Business, Duke University, pp. 1-8, 2014. [Online]. Available at: https://people.duke.edu/ rnau/Notes_on_forecasting_with_moving_averages--Robert_Nau.pdf.

[27] V. Gaspersz, "Production planning and inventory control," Jakarta: Vincent Foundation and PT Gramedia Pustaka Umum, 2004.

[28] G. W. Plossl and O. W. Wight, "Production and Inventory Control," Prentice Hall, $1^{\text {st }}$ Edition, 1985.

[29] Surveillance Officers, "Data on the number of Dengue Hemorrhagic Fever patients at Muara Badak Health Center in 2017 and 2018," Muara Badak Health Center, 2019.

\section{BIOGRAPHIES OF AUTHORS}
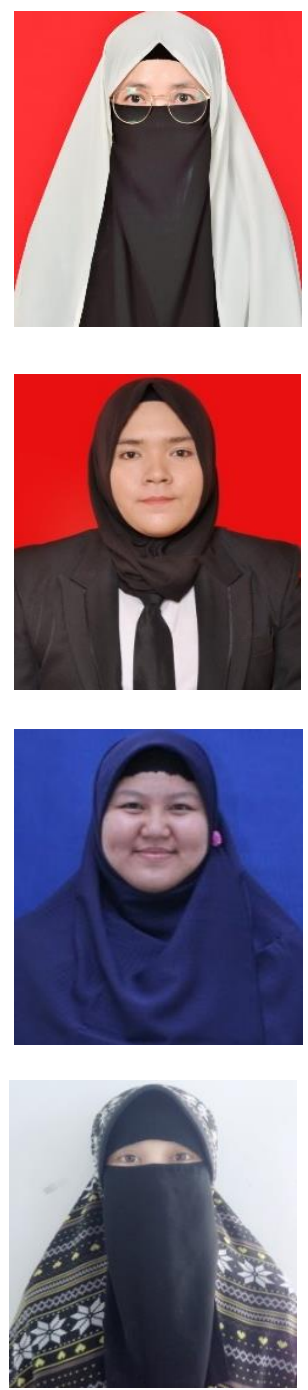

Dyna Marisa Khairina, was born in Samarinda, East Kalimantan, Indonesia in March $5^{\text {th }} 1984$. She received her Bachelor of Degree in Computer Science of Mulawarman University, Indonesia in 2007. She received her Master of Information System degree at Diponegoro University, Semarang, Indonesia in 2012. She is working as a lecture in the Department of Information System Universitas Mulawarman, Samarinda, Indonesia since 2008. Her research interest are information system, decision support system, enterprise architecture and management information system. She is member of APTIKOM (Association of Computing and Informatics Institution Indonesia) and AISINDO (Association for Information Systems Indonesia). Email: dyna.ilkom@gmail.com

Rizka Khairunnisa, was born in Samarinda, East Kalimantan, Indonesia in November $19^{\text {th }}$, 1997. He received her Bachelor of Degree in Computer Science of Universitas Mulawarman, Indonesia in 2019. Her research interest are information system and decision support system. Email: rizkakhairunnisa77@gmail.com

Heliza Rahmania Hatta, was born in Samarinda, July $15^{\text {th }} 1985$, received Bachelor of Computer Science from Mulawarman University. Master of Informatics Engineering from Institut Teknologi Sepuluh Nopember, Surabaya, Indonesia in 2013. Currently her is a lecturer at Department of Informatics in Mulawarman University, Samarinda, East Kalimantan, Indonesia since 2008. Her research areas of interest are artificial intelligence, decision support system, expert system, information system and information technology. She is member of APTIKOM (Association of Computing and Informatics Institution Indonesia). Email: heliza_rahmania@yahoo.com

Septya Maharani, was born in Samarinda, September $29^{\text {th }} 1984$, received Bachelor of Computer Science from Mulawarman University. Master of Information System from Diponogoro University, Semarang, Indonesia in 2012. Currently her is a lecturer at Department of Information System in Mulawarman University, Samarinda, East Kalimantan, Indonesia since 2008. Her research areas of interest are decision support system, expert system, information system and computer and human interaction. She is member of APTIKOM (Association of Computing and Informatics Institution Indonesia) and AISINDO (Association for Information Systems Indonesia). Email: septyamaharani@gmail.com 